\title{
If You Listen, I Will Talk: the Experience of Being Asked About Suicidality During Routine Primary Care
}

\author{
Julie E. Richards, $M P H^{1,2}$, Sarah D. Hohl, $M P H^{2}$, Ursula Whiteside, $P h D^{3}$, \\ Evette J. Ludman, $P h D^{\prime}$, David C. Grossman, MD, MPH ${ }^{1,2,4}$, Greg E. Simon, MD, MPH, \\ Susan M. Shortreed, PhD ', Amy K. Lee, MPH', Rebecca Parrish, LICSW' ${ }^{5}$, Mary Shea, MA' ${ }^{\prime}$, \\ Ryan M. Caldeiro, $M D^{5}$, Robert B. Penfold, $P h D^{1,2}$, and Emily C. Williams, $P h D, M P H^{1,2,6}$
}

'Kaiser Permanente Washington Heath Research Institute, Seattle, WA, USA; '2Department of Health Services, University of Washington, Seattle, WA, USA; ${ }^{3}$ NowMattersNow. org, Seattle, WA, USA; ${ }^{4}$ Department of Preventive Care, Kaiser Permanente Washington, Seattle, WA, USA; ${ }^{5}$ Mental Heath \& Wellness, Kaiser Permanente Washington, Seattle, WA, USA; ${ }^{\circ}$ Health Services Research \& Development (HSR\&D), Center of Innovation for VeteranCentered Value-Driven Care, Veterans Affairs (VA) Puget Sound Health Care System, Seattle, WA, USA.

BACKGROUND: Routine population-based screening for depression is an essential part of evolving health care models integrating care for mental health in primary care. Depression instruments often include questions about suicidal thoughts, but how patients experience these questions in primary care is not known and may have implications for accurate identification of patients at risk. OBJECTIVES: To explore the patient experience of routine population-based depression screening/assessment followed, for some, by suicide risk assessment and discussions with providers.

DESIGN: Qualitative, interview-based study.

PARTICIPANTS: Thirty-seven patients from Kaiser Permanente Washington who had recently screened positive for depression on the 2-item Patient Health Questionnaire [PHQ] and completed the full PHQ-9.

APPROACH: Criterion sampling identified patients who had recently completed the $\mathrm{PHQ}-9$ ninth question which asks about the frequency of thoughts about self-harm. Patients completed semi-structured interviews by phone, which were recorded and transcribed. Directive and conventional content analyses were used to apply knowledge from prior research and elucidate new information from interviews; thematic analysis was used to organize key content overall and across groups based on endorsement of suicide ideation.

KEY RESULTS: Four main organizing themes emerged from analyses: (1) Participants believed being asked about suicidality was contextually appropriate and valuable, (2) some participants described a mismatch between their lived experience and the $\mathrm{PHQ}-9$ ninth question, (3) suicidality disclosures involved weighing hope for help against fears of negative consequences, and (4) provider relationships and acts of listening and caring facilitated discussions about suicidality.

CONCLUSIONS: All participants believed being asked questions about suicidal thoughts was appropriate, though some

Electronic supplementary material The online version of this article (https://doi.org/10.1007/s11606-019-05136-x) contains supplementary material, which is available to authorized users.

Received July 30, 2018

Revised February 21, 2019

Accepted May 9, 2019

Published online July 25, 2019 who disclosed suicidal thoughts described experiencing stigma and sometimes distanced themselves from suicidality. Direct communication with trusted providers, who listened and expressed empathy, bolstered comfort with disclosure. Future research should consider strategies for reducing stigma and encouraging fearless disclosure among primary care patients experiencing suicidality.

KEY WORDS: suicidal ideation; suicidality; depression screening; suicide assessment; qualitative.

J Gen Intern Med 34(10):2075-82

DOI: $10.1007 / \mathrm{s} 11606-019-05136-\mathrm{x}$

(C) Society of General Internal Medicine 2019

\section{INTRODUCTION}

Behavioral health care is being increasingly integrated into primary care settings. ${ }^{1}$ Population-based screening for depression is an essential part of behavioral health integration and is recommended by experts in primary care settings to ensure patients in need of care are accurately identified. ${ }^{2,3}$ Though the US Preventive Services Task Force has identified insufficient evidence to endorse widespread recommendations for screening for suicide risk, depression screening instruments often include questions about suicidal ideation and these questions have been shown to predict subsequent suicide attempts. ${ }^{4-6}$ For example, the 9-item Patient Health Questionnaire [PHQ-9] is broadly used to identify patients with depression, and the ninth question asks about frequency of "thoughts you would be better off dead, or of hurting yourself in some way" in the past two weeks. ${ }^{7}$

It is not currently possible to know when or if patients are suicidal by means other than asking directly. Because nearly half of persons who die by suicide have a primary care visit in the month prior to their death, ${ }^{8,9}$ and studies have identified that endorsement of suicidal thoughts on screening questions has predicted subsequent suicide attempts/deaths, ${ }^{4-6}$ asking patients routine questions about suicidality (suicidal ideation, intent, and plans) in primary care settings may be a critical preventive measure. ${ }^{10}$ However, the link between asking patients about suicidality and the ability of providers and health 
systems to help prevent suicide is unclear. For instance, one study showed one-fourth of suicide attempts occurring within a week of patients completing the PHQ-9 were among patients responding "not at all" to the ninth question. ${ }^{5}$ It is possible that these patients were not experiencing suicidal thoughts at the time of the visit; it is also possible that patients underreport suicidal thoughts or misinterpret the questions.

Previous studies have explored reasons some suicide attempt survivors did not report suicidal ideation prior to attempt ${ }^{11}$ and Veterans' experiences of a suicide risk assessment process. ${ }^{12}$ However, additional research is needed to understand how primary care patients experience and answer questions about suicidal ideation in the context of routine depression screening. Therefore, we conducted semi-structured qualitative interviews with a sample of primary care patients who screened positive for depression and were assessed for symptom severity with the PHQ-9. Though all patients screened positive for depression, not all endorsed suicidal ideation; a portion were offered more comprehensive assessment for suicide risk. Thus, we purposively stratified our sampling based on endorsement of suicidal ideation to understand perceptions of primary care patients with varying experiences of depression screening and suicide risk assessment.

\section{METHODS}

\section{Study Setting}

The study was conducted at Kaiser Permanente [KP] Washington, where primary care patients are given a 7-item self-administered paper questionnaire by a receptionist or medical assistant prior to their visit, including the PHQ-2 for depression, ${ }^{13}$ and questions about substance use ${ }^{14-17}$ to prompt discussions with providers and guide clinical decision-making. Patients are asked to complete the remaining seven questions of the PHQ-9 when their response to the PHQ-2 is positive ( $\geq 2$ on either question). ${ }^{7}$ Patients who score 2 "more than half the days" or 3 "nearly every day" on the PHQ-9 ninth question are asked to complete a selfadministered paper version of the Columbia Suicide Severity Rating Scale [C-SSRS] (see www.cssrs.columbia.edu). ${ }^{18-20}$ For patients endorsing any past month planning for suicide attempt, staff are prompted to initiate a same-day referral to a primary care social worker or registered nurse for collaborative safety planning. ${ }^{21-23}$

\section{Study Sample}

We used electronic medical record [EMR] data to identify eligible patients $(N=100)$ who had screened positive on the PHQ-2 and completed the PHQ-9. We used a purposive sampling distribution defined by specific criteria ${ }^{24}$ to recruit demographically diverse patients endorsing across the full PHQ-9 ninth question options of thought about self-harm $(N=30$ "not at all," $N=20$ "several days," $N=20$ "more than half the days," $N=30$ "nearly every day") and some who were further assessed by the C-SSRS.
We aimed to interview 30-40 participants to maximize thematic saturation. We excluded minors $(<18)$ and anyone currently enrolled in a suicide prevention trial.

Eligible patients received an invitation letter and information sheet describing the study purpose and procedures, how they were selected, and a phone number to opt-out. Interviews were conducted as soon as possible following screening to help patients accurately recall their experiences. ${ }^{25}$ Participants provided oral consent by phone and received $\$ 50$ for participation. All study procedures were approved by the KP Institutional Review Board.

\section{Telephone Interview}

Two psychologists (UW, EL) and one health services researcher (JR), all trained in qualitative interview techniques, conducted audio-recorded interviews by telephone. The interview guide (online appendix) was designed, mindful of suiciderelated stigma, to begin with general questions to help build rapport before probing participants for details about their experiences with questions about suicidal ideation and suicide risk when applicable. Question development considered previous research regarding why providers may choose not to discuss suicide risk with patients ${ }^{26}$ and may address suicidal thoughts in unhelpful or harmful ways, ${ }^{27,}{ }^{28}$ as well as patient perspectives on the PHQ-9 questions. ${ }^{29}$

\section{Analysis}

We summarized the demographic and patient-reported characteristics of participants and compared participants' responses with the PHQ-9 ninth question on thoughts of self-harm (also used for sampling). Audio-recordings of interviews were professionally transcribed and uploaded into Atlas. $\mathrm{ti}^{30}$ for qualitative analysis along with their screening and assessment data from the participants' EMRs. We used a combination of directive content analysis (deductive) to apply knowledge from prior research and conventional (inductive) content analysis, ${ }^{31}$ to elucidate new information about the patient experience. Interviews were coded by investigators trained in qualitative methods (JR, SH) using a set of codes developed a priori based on the interview guide. Both coders added and refined codes iteratively through independent review, followed by several rounds of comparison and discussion. Once all interviews were coded by at least 1 coder (10 interviews were coded by both), the coders created an affinity diagram to organize codes into a thematic network, ${ }^{32}$ and assessed whether themes differed based on report of thoughts about self-harm. The full investigative team refined themes and agreed on prototypic examples.

\section{RESULTS}

\section{Participant Characteristics and Screening Results}

Of patients sampled $(N=100), 11$ refused participation, 12 were unreachable, and 37 were interviewed before recruitment 
ended when thematic saturation was reached. Interviews lasted an average duration of 15.4 min (ranging 5-29). Participants included men and women age 20-95 (Table 1). All participants had current depressive symptoms at the time of their visit (mean PHQ-9 score = 17.6, SD 6.4), and those who endorsed having some thoughts about self-harm on the PHQ-9 ninth question $(N=28)$ reported greater symptom severity (PHQ-9 mean score 20.1 versus $9.7, p<.0001)$.

Table 1 Participant Characteristics and Screening Results

\begin{tabular}{|c|c|c|c|c|c|c|}
\hline & \multirow[b]{3}{*}{$N$} & \multirow[b]{3}{*}{$\%$} & \multicolumn{4}{|c|}{$\begin{array}{l}\text { PHQ-9 Q9 thoughts of self- } \\
\text { harm (past } 2 \text { weeks) }\end{array}$} \\
\hline & & & \multicolumn{2}{|c|}{ Score $=0$} & \multicolumn{2}{|c|}{ Score $=1-3$} \\
\hline & & & $N$ & $\%$ & $N$ & $\%$ \\
\hline Female & 25 & $68 \%$ & 7 & $78 \%$ & 18 & $64 \%$ \\
\hline \multicolumn{7}{|l|}{ Age category } \\
\hline $20-35$ & 11 & $30 \%$ & 1 & $11 \%$ & 10 & $36 \%$ \\
\hline $36-50$ & 11 & $30 \%$ & 4 & $44 \%$ & 7 & $25 \%$ \\
\hline $51-70$ & 10 & $27 \%$ & 0 & $0 \%$ & 10 & $36 \%$ \\
\hline$>70$ & 5 & $14 \%$ & 4 & $44 \%$ & 1 & $4 \%$ \\
\hline \multicolumn{7}{|l|}{ Race/ethnicity } \\
\hline White & 28 & $76 \%$ & 5 & $76 \%$ & 23 & $82 \%$ \\
\hline Black & 3 & $8 \%$ & 2 & $22 \%$ & 1 & $4 \%$ \\
\hline Asian & 2 & $5 \%$ & 1 & $11 \%$ & 1 & $4 \%$ \\
\hline Hispanic & 2 & $5 \%$ & 0 & $0 \%$ & 2 & $7 \%$ \\
\hline Am Indian & 1 & $3 \%$ & 1 & $11 \%$ & 0 & $0 \%$ \\
\hline Unknown & 1 & $3 \%$ & 0 & $0 \%$ & 1 & $4 \%$ \\
\hline \multicolumn{7}{|c|}{ AUDIT-C alcohol use category } \\
\hline Non-drinker & 13 & $35 \%$ & 3 & $33 \%$ & 10 & $36 \%$ \\
\hline $\begin{array}{l}\text { Low risk } \\
\text { (women } 1-2, \text { men } 1-3 \text { ) }\end{array}$ & 11 & $30 \%$ & 3 & $33 \%$ & 8 & $29 \%$ \\
\hline $\begin{array}{l}\text { (women } 1-2, \text { men } 1-3 \text { ) } \\
\text { Moderate risk } \\
\text { (women 3-7, men 4-7) }\end{array}$ & 11 & $30 \%$ & 3 & $33 \%$ & 8 & $29 \%$ \\
\hline $\begin{array}{l}\text { High risk (women and } \\
\text { men } \geq 7 \text { ) }\end{array}$ & 0 & $0 \%$ & 0 & $0 \%$ & 0 & $0 \%$ \\
\hline Did not answer & 2 & $5 \%$ & 0 & $0 \%$ & 2 & $7 \%$ \\
\hline \multicolumn{7}{|c|}{ Illicit drug use (any past year) } \\
\hline Yes & 2 & $5 \%$ & 0 & $0 \%$ & 2 & $7 \%$ \\
\hline No & 33 & $89 \%$ & 9 & $100 \%$ & 24 & $86 \%$ \\
\hline Did not answer & 2 & $5 \%$ & 0 & $0 \%$ & 2 & $7 \%$ \\
\hline \multicolumn{7}{|c|}{ Marijuana use (any past year) } \\
\hline Yes & 7 & $19 \%$ & 0 & $0 \%$ & 2 & $7 \%$ \\
\hline No & 27 & $73 \%$ & 9 & $100 \%$ & 24 & $64 \%$ \\
\hline Did not answer & 3 & $8 \%$ & 0 & $0 \%$ & 2 & $11 \%$ \\
\hline $\begin{array}{l}\text { PHQ-9 score (mean, } \\
\text { SD) }\end{array}$ & 17.6 & 6.4 & 9.7 & 4.7 & 20.1 & 4.5 \\
\hline \multicolumn{7}{|l|}{ PHQ-9 category } \\
\hline Mild (5-9) & 6 & $16 \%$ & 6 & $22 \%$ & 0 & $0 \%$ \\
\hline Moderate $(10-14)$ & 4 & $11 \%$ & 0 & $0 \%$ & 4 & $14 \%$ \\
\hline $\begin{array}{l}\text { Moderately severe } \\
(15-19)\end{array}$ & 8 & $22 \%$ & 3 & $11 \%$ & 5 & $18 \%$ \\
\hline Severe (20-27) & 19 & $51 \%$ & 0 & $0 \%$ & 19 & $68 \%$ \\
\hline \multicolumn{7}{|l|}{ PHQ-9 Q9 } \\
\hline Never $(0)$ & 9 & $24 \%$ & & & & \\
\hline Several days (1) & 8 & $22 \%$ & & & & \\
\hline $\begin{array}{l}\text { More than half the } \\
\text { days (2) }\end{array}$ & 11 & $30 \%$ & & & & \\
\hline Nearly every day (3) & 9 & $24 \%$ & & & & \\
\hline *C-SSRS received & 14 & $38 \%$ & & & & \\
\hline Score 0 & 1 & $7 \%$ & & & & \\
\hline Score 1 & 5 & $36 \%$ & & & & \\
\hline Score 2 & 3 & $21 \%$ & & & & \\
\hline Score 3 & 2 & $14 \%$ & & & & \\
\hline Score 4 & 1 & $7 \%$ & & & & \\
\hline Score 5 & 1 & $7 \%$ & & & & \\
\hline Score 6 & 1 & $7 \%$ & & & & \\
\hline
\end{tabular}

*Routinely administered only to patients who score 2 or 3 on the PHQ-9 ninth question at KP Washington. Score = number of highest question endorsed, indicating greater suicide risk severity

\section{Organizing Themes}

Four organizing themes emerged from analysis (see Fig. 1): (1) Participants believed being asked about suicidality was contextually appropriate and valuable, (2) some participants described a mismatch between their lived experience and the PHQ-9 ninth question, (3) suicidality disclosures involved weighing hope for help against fears of negative consequences, and (4) provider relationships, and acts of listening and caring facilitated discussions about suicidality.

\section{Theme 1: Participants Believed Being Asked About Suicidality Was Contextually Appropriate and Valuable}

All participants, with and without reported thoughts of self-harm, said depression screening followed by suicidality assessment was appropriate in the context of a primary care visit. Participants specifically described how the questionnaires provided important information to their doctors: "Well, I just think that when you go into, especially a new primary care doctor, that they know all of the basic history, and that is part of history for a lot of people (P8)." Participants described how questions are a way to get help, as one asserted, "definitely appropriate, especially in regard to trying to discuss with [providers] options to treat depression (P14)." Other participants described how the questions were "good for screening (P2)" and "predicting what may happen to my health (P13)," as well as the necessity to ask because, "I think it's the only way they can judge [mental health] (P6)."

Other participants described how the questions were valuable for self-reflection: "I feel like it's also just a good gauge for me as a person... it reminds me, 'Oh, well, this is something I've experienced in the past two weeks (P4)." However, participants also said selfreflection about suicidality could be difficult, though still important to ask about:

It's always difficult, kind of the [questions] of self-harm and suicide, but I think it's important to ask... You don't want to have these thoughts. Yet you have them. I don't like it but the way I answer it is the truth (P37).

Similarly, another participant described questions about depression and self-harm as "relevant" and "important," but found it difficult to share about a topic generally kept private:

Whenever I fill one of those things out I feel like all of them are uncomfortable, only because it's making you take a look at yourself and it's sometimes really hard to be honest with yourself when you have a problem. So, it's always uncomfortable because it's letting somebody that you don't know into probably the deepest secrets you have (P17). 


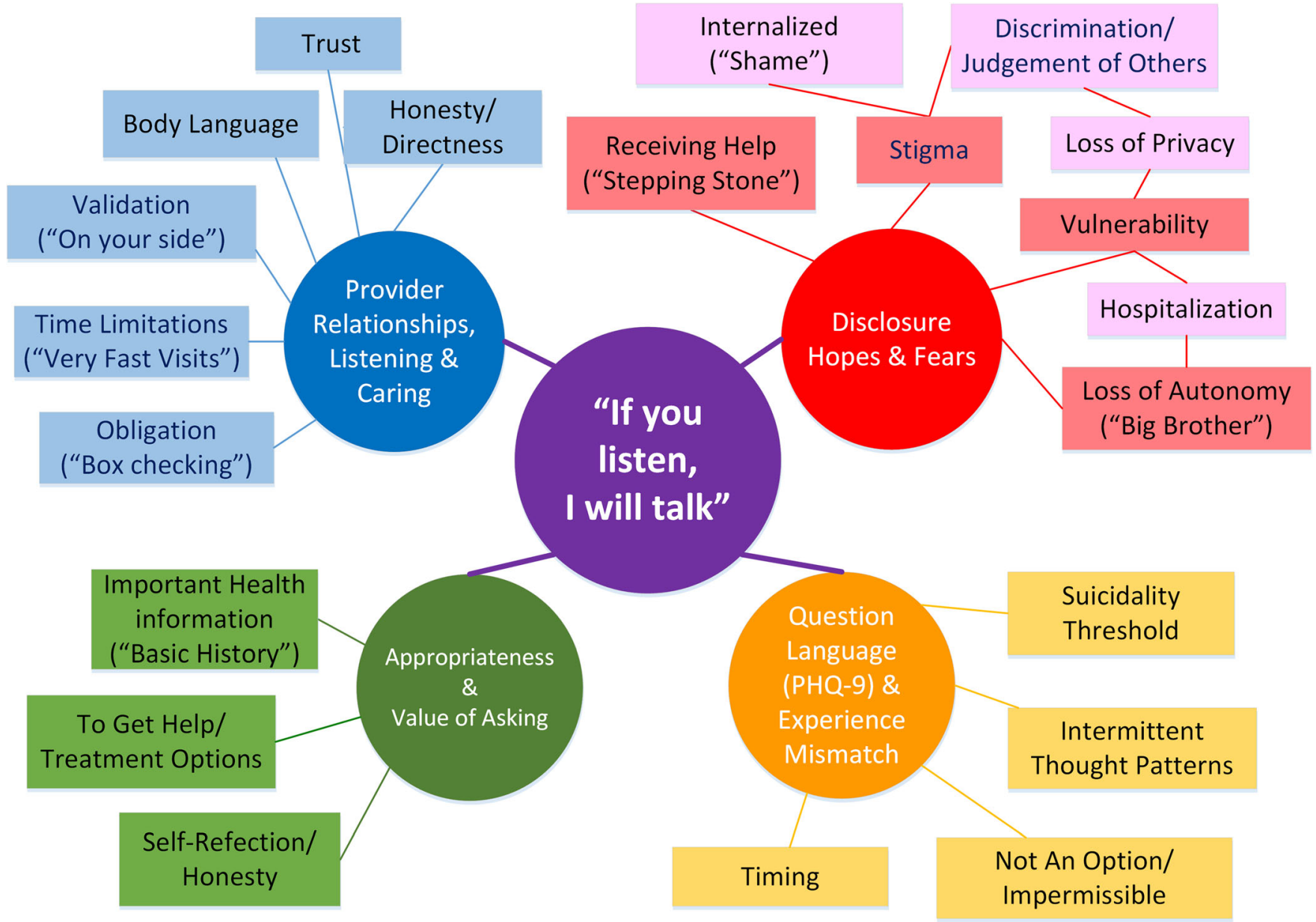

Figure 1 Thematic analysis of the patient experience being asked about suicidality in primary care setting.

\section{Theme 2: Some Participants Described a Mismatch Between Their Lived Experience and the PHQ-9 Ninth Question}

Some participants, primarily those who reported thoughts of self-harm, felt language in the PHQ-9 ninth question did not fit their experience. Several alluded to a threshold for being "suicidal" and one described how their thoughts were more about escaping current problems:

That question isn't applicable because I'm not suicidal... my feeling is like running away or wanting to abandon all my problems...there's people like that out there who feel like that and aren't quite suicidal, but they are at the edge (P4).

Another described how the timing of the question affected their answer:

I was just kind of DONE at the moment... it was hard for me to answer because at the moment I wanted to, you know, say all that but I probably didn't because that's not TRULY how I feel (P3).
Similarly, a participant described thinking about suicide more frequently but was not presently planning to act on those thoughts:

It wasn't like, “Oh, my God. I want to go out tomorrow and do it." But it's something that I do think about... I don't feel like I need to go jump off a bridge and hang myself today, but it's a catchy one. So, how do I say that (P35)?Another described how the intermittent pattern of their suicidal thoughts made it difficult to answer, how do you say what you need to say? ...It's just something that comes out and it goes - I've thought about it and forgot about it, type thing (P11).

Other participants described how language about suicide does not account for family responsibilities or religious values. One said, "yes, I would love to disappear, but I also believe in staying around for my children (P9)." Another described, "I wasn't exactly sure how to answer it because I'm a Christian; therefore, I'm not going to kill myself but perhaps I didn't want to be here and, therefore, you can answer that question several different ways (P21)." 


\section{Theme 3: Suicidality Disclosures Involved Weighing Hope for Help Against Fears of Negative Consequences}

Many participants, with and without reported thoughts of selfharm, described a complex relationship between disclosing suicidality in hopes of receiving help, balanced with the fear of stigma, vulnerability, and loss of autonomy. Those who expected their provider would use the information like a "stepping-stone" to get them the help they needed described an easier time answering: "I know I need help somewhere along the line, and it was easier to answer the questions so they knew where I was at (P15)." Another described, "I answered it with confidence because I wanted her to help me (P5)." Many participants explained that they perceived their response as a choice, based on a desire for help, or lack thereof: "it just depends on how bad the person wants the help. If they don't want the help that much, they're probably not gonna answer the questionnaire (P15)." However, even patients who desired help and planned to disclose their needs had fears about the outcome:

I was there to seek out help for some reckless behavior on my part... and hopefully seek out some sort of support system for the first time. So, I was not uncomfortable answering those questions honestly. If anything, I was scared about how the response was going to be after the fact (P14).

Participants described fear of different manifestations of stigma. One described how making the choice to ask for help often means labeling oneself with a stigmatized condition:

You don't really want any help because once you go into that system, you are forever - certainly in your own mind, and also in the minds of people that know you're going there - you're a person with that kind of problem, a mental health issue, and that is quite a stigma (P2).

Similarly, patients described fear of judgment from family members, friends, or coworkers:

I don't know if that was just me, but first thing I'm thinking is, "Oh, my God. I don't want my kids to know. I don't want my work to know."... you want them to know some, but not all because it's kind of a real funky area... I don't want them to think that I'm losing it or - I'm not too sure what they'll think (P35).

One participant described experiencing "shame" and vulnerability during depressive episodes:

There are still parts where you feel shame and different things. When you're out of the depression, you don't feel that way. When you're in it, you want to protect the way you feel (P37).
However, some participants who described themselves as "older" with more mental health care experiences described how their vulnerability had diminished:

If I go back many, many years ago, that question would have scared me. But I've been answering these for a long time, so they don't bother me at all anymore (P10).

Participants also expressed different fears about the loss of autonomy. One referred to the PHQ-9 ninth question as a "Big Brother" question and the sense that disclosing suicidality may lead to care outside their control, "especially with mental health patients, you're not ever sure what is going to be the reaction to what I'm experiencing. Will I have to be taken somewhere or taken care of in a certain way (P4)?" Another echoed this fear:

I mean even if I did have those thoughts I don't think I would say yes to that just because... like I said I don't know what would happen to me and whether something would happen involuntarily... I guess it's just what I imagine in movies or something that whether I'd get - not be able to return home to my family (P26).

Similarly, other participants described fears of, "being locked up in a white padded room (P35)" or that "people in white jumpsuits are gonna jump in and take me out of the room (P4)." One participant described the experience of being hospitalized and how providers may address this topic to alleviate fear:

When I was a kid, I went to a therapist. And he basically asked that question, do you wanna be alive? And I couldn't say yes because I didn't wanna be. But at the same time, I was not suicidal... and couldn't say yes to that question. So, they put me in a hospital for three days...if anybody else knows that and they're afraid of that, just being upfront and saying, "Say how you really feel, you won't necessarily go to a hospital unless you're actively thinking about hurting yourself (P18).”

His sentiment was repeated by other participants who worried the information they disclosed about suicidal ideation may preclude them from leaving the provider's office.

\section{Theme 4: Provider Relationships, and Acts of Listening and Caring Facilitated Discussions About Suicidality}

Many participants, with and without reported thoughts of selfharm, described how trusting relationships they had built with their providers over time, as well as listening and caring, facilitated discussions about suicidality. One participant said, 
"My health provider, she can ask anything she wants to. I mean, she has really known me long enough and so has her aid... They're part of my entire family, which includes my healthcare people (P33)." Another called their provider their "rock" and said, "He's been through everything with me... I wouldn't be here today if it hadn't been for him... And I didn't have any secrets with Dr. X because he went through so much with me, he didn't deserve secrets (P10)." Another described how honesty was implicit in their patient-provider relationship: "I've built up a relationship with my physician...He already knows how I am, so he can probably get a better clue if I'm actually lying to him or if I'm actually telling the truth (P1)." Participants also described how open and direct communication facilitated honesty and alleviated vulnerability: "I trusted her to tell her everything that I was going through and what I was feeling. And she felt very candid to tell me, you know, what I needed to do without hurting my feelings (P27)."

Participants also described how interactions with providers could be improved with specific expressions of listening and caring. Participants described the experience of feeling like the provider was only asking about suicide risk out of obligation, "I feel like when I was asked the questionnaire, it was like reading off a script and more or less checking boxes rather than I'm afraid for your safety (P17)." One gave a suggestion about body language, "Sit down and talk face to face, don't be standing at the doorway ready to leave (P6)." Similarly, others described how their visits were "very fast" and not knowing if their provider had looked at their questionnaire due to time limitations. Participants also expressed desire for validation, "Let's see what we can do to get this done. We're on your side. We're here to help (P25)." Another participant described expressions of listening and caring were more important than finding an immediate solution to their problems:

I wish it all could have been done over again with my primary care provider, actually. To be a good listener, when I'm there crying and not knowing what to do, that's the thing. When somebody's coming in and they're vulnerable and they're depressed and they're overwhelmed by emotions, I'm sure it can be intimidating... It's just like compassion. Don't try to fix it today. Try to first just listen (P37).

\section{DISCUSSION}

To our knowledge, this qualitative study among primary care patients who had recently been asked about their frequency of thoughts about self-harm, using the PHQ-9 ninth question, is the first to investigate the patient experience of being asked about suicidality as part of population-based depression screening and symptom severity assessment. All participants, regardless of their PHQ-9 ninth question response, believed it was appropriate for their health care providers to ask about self-harm because it can provide important health information to their providers, and offer valuable self-reflection. However, participants who reported thoughts of self-harm sometimes felt the PHQ-9 ninth question was difficult to answer because it did not adequately reflect their lived experience. Participants described how questions about suicidal thoughts generate fear of stigma, vulnerability, and/or loss of autonomy. Expressions of listening and caring and direct communication with trusted providers appeared to bolster participants' comfort with disclosures. Though we did not explicitly assess relationships with providers, these findings support prior research that "protective benevolence" is unhelpful ${ }^{33}$ and providers perceived as focused on building a relationship through genuineness and empathy promoted trust, resulting in more honest disclosure of suicidal thoughts. ${ }^{12}$ Findings from the present study may be useful for primary care practices navigating the benefits and costs of integrating care for depression and suicidality, consistent with current depression screening recommendations. ${ }^{2,3}$

Participants' descriptions of the mismatch between their lived experiences and the PHQ-9 ninth question were noteworthy. The PHQ-9, designed to measure depression severity, does not explicitly ask about suicidal thoughts; but participants understood that to be the meaning of the question and some described the term "suicide" as being more severe than what they were experiencing, even when they had thoughts about ending their own lives. Participants also distanced themselves from this term due to family responsibilities or religious beliefs, which is unsurprising given religious norms prohibiting suicide. ${ }^{34}$ Nonetheless, this experience may reflect a separation between desire and capacity for suicide. ${ }^{35}$ Suicide risk assessments, like the C-SSRS, are designed to explicitly distinguish between suicidal thoughts and plans; ${ }^{19,20,36}$ however, the PHQ-9 is often used as indication for suicide risk assessment, so when patients distance themselves from the notion of having suicidal thoughts, they may not be offered more comprehensive suicide risk. Future research is needed to identify and evaluate strategies for reducing suicide-related stigma and encouraging fearless disclosure among primary care patients experiencing suicidality.

Participants in this study described weighing desire for help against fears of stigma, vulnerability, and loss of autonomy. Recent qualitative findings among suicide attempt survivors suggest this cost-benefit analysis is important when deciding about disclosing suicidality to friends and family members. ${ }^{37}$ Participants described the fear of stigma in different ways, including internalized "shame," fear of labeling oneself, and fear of vulnerability to judgment by friends and family members. These fears are predictable - stigma and discrimination related to mental illness is well-documented at the patient, ${ }^{38}$ health care, ${ }^{33,} 39$ and societal levels. ${ }^{40}$ Participants also expressed vulnerability regarding potential loss of autonomy and involuntary hospitalization, invoking movie-like descriptions of padded rooms and people in white jumpsuits. While these images may not be an accurate representation of the psychiatric hospitalization experience today, the idea of being locked in an inpatient psychiatric unit causes fear, ${ }^{41,}{ }^{42}$ which 
is reinforced by descriptions of negative experiences among patients hospitalized for suicidality. Further research is needed to evaluate whether orienting patients about what to expect if they endorse suicidal thoughts may be key to facilitating assessment of suicide risk and care needs.

This study has several limitations. First, though developed based on a thorough literature review and intended to elicit open-ended unstructured information from participants, the interview guide included several closed-ended questions, which may have encouraged participants to respond in specific ways and/or limited information obtained from participants. Although qualitative research is not intended to be generalizable, several features of the sample indicate a need for additional research in other populations. Specifically, patients were selected from one health system that recently integrated population-based screening for depression and substance use into routine primary care, which may not reflect experiences of patients assessed for suicide risk in other systems using other processes (e.g., provider-administered). Moreover, all participants reported depressive symptoms and most endorsed relatively frequent thoughts of self-harm at their most recent primary care visit. Therefore, although we attempted to capture the full potential range of experiences, findings may not be generalizable to typical primary care populations. It is possible that patients who do not endorse depressive symptoms or fail to respond would have different, potentially less accepting, opinions of questions about suicidal ideation. Finally, the sample was not racially or culturally diverse. Future research is needed within larger broadly representative populations, including less severely affected patients, adolescents, and those who choose not to answer screening questionnaires, as well as communities that may culturally define suicide in different ways. ${ }^{43}$

\section{CONCLUSIONS}

This qualitative study reports patient experiences of being screened for suicidality. Strong trusting relationships with providers alleviated patients' vulnerability disclosing suicidal thoughts. Expressions of caring and active listening, without panic or raising unnecessary alarm, are perhaps more important than immediate problem-solving, and may bolster patients comfort with disclosing stigmatized information they fear will compromise their autonomy. Findings are relevant to primary care practices considering implementation of procedures supporting routine depression screening followed by suicide risk assessment in accordance with national recommendations. Health systems may consider adding language to selfadministered questionnaires that normalize suicidal thoughts and reassure patients their providers will use the information to help them access care they may need.

Acknowledgments: The authors gratefully acknowledge the participants in this study for sharing their time and valuable experiences.
Corresponding Author: Julie E. Richards, MPH; Kaiser Permanente Washington Heath Research Institute, Seattle, WA, USA (e-mail: Julie. E.Richards@kp.org).

Funding Information This study was funded by a Development Fund from the Kaiser Permanente Washington Health Research Institute to Julie Richards. Dr. Williams was supported by a Career Development Award \#12-276 from the US Department of Veterans Affairs Health Services Research and Development (HSR\&D) Program at the time this research was conducted.

\section{Compliance with Ethical Standards:}

Conflict of Interest: The authors declare they do not have a financial conflict of interest related to this manuscript.

\section{REFERENCES}

1. Gerrity M. Evolving Models of Behavioral Health Integration: Evidence Update 2010-2015. Milbank Memorial Fund; 2016.

2. Siu AL, Bibbins-Domingo $\mathbf{K}$, Grossman DC, et al. Screening for Depression in Adults: US Preventive Services Task Force Recommendation Statement. JAMA. 2016;315(4):380-387.

3. National Committee for Quality Assurance. Depression Screening and Follow-Up for Adolescents and Adults (DSF). HEDIS 2019 Volume 2: Technical Specifications for Health Plans. Vol 2. Washington, DC: National Committee for Quality Assurance; 2018.

4. Simon GE, Coleman KJ, Rossom RC, et al. Risk of suicide attempt and suicide death following completion of the Patient Health Questionnaire depression module in community practice. J Clin Psychiatry 2016;77(2):221-227.

5. Simon GE, Rutter CM, Peterson D, et al. Does response on the PHQ-9 Depression Questionnaire predict subsequent suicide attempt or suicide death? Psychiatr Serv 2013;64(12):1195-1202.

6. Louzon SA, Bossarte R, McCarthy JF, Katz IR. Does Suicidal Ideation as Measured by the PHQ-9 Predict Suicide Among VA Patients? Psychiatr Serv 2016;67(5):517-522.

7. Kroenke K, Spitzer RL, Williams JB. The PHQ-9: validity of a brief depression severity measure. J Gen Intern Med 2001;16(9):606-613.

8. Luoma JB, Martin CE, Pearson JL. Contact with mental health and primary care providers before suicide: a review of the evidence. Am J Psychiatry 2002;159(6):909-916.

9. Ahmedani BK, Simon GE, Stewart C, et al. Health care contacts in the year before suicide death. J Gen Intern Med 2014;29(6):870-877.

10. Joint Commission. Detecting and treating suicide ideation in all settings. Sentinel Event Alert 2016;56:1-7.

11. Richards JE, Whiteside U, Ludman EJ, et al. Understanding Why Patients May Not Report Suicidal Ideation at a Health Care Visit Prior to a Suicide Attempt: A Qualitative Study, Psychiatr Serv 2019;70:40-45.

12. Ganzini L, Denneson LM, Press N, et al. Trust is the basis for effective suicide risk screening and assessment in veterans. J Gen Intern Med 2013;28(9): 1215-1221.

13. Kroenke K, Spitzer RL, Williams JB. The Patient Health Questionnaire-2: validity of a two-item depression screener. Med Care 2003;41(11):1284-1292.

14. Bradley KA, DeBenedetti AF, Volk RJ, Williams EC, Frank D, Kivlahan DR. AUDIT-C as a brief screen for alcohol misuse in primary care. Alcohol Clin Exp Res 2007;31(7):1208-1217.

15. Bush K, Kivlahan DR, McDonell MB, Fihn SD, Bradley KA. The AUDIT alcohol consumption questions (AUDIT-C): an effective brief screening test for problem drinking. Ambulatory Care Quality Improvement Project (ACQUIP). Alcohol Use Disorders Identification Test. Arch Intern Med 1998;158(16):1789-1795.

16. Bobb JF, Lee AK, Lapham GT, et al. Evaluation of a Pilot Implementation to Integrate Alcohol-Related Care within Primary Care. Int J Environ Res Public Health. 2017; 14(9).

17. Lapham GT, Lee AK, Caldeiro RM, et al. Frequency of Cannabis Use Among Primary Care Patients in Washington State. J Am Board Fam Med 2017;30(6):795-805.

18. The Columbia Lighthouse Project. The Columbia Scale (C-SSRS): About the Protocol. 2016. http://cssrs.columbia.edu/the-columbia-scale-cssrs/about-the-scale/. Accessed 6 May 2019. 
19. Posner K, Brown GK, Stanley B, et al. The Columbia-Suicide Severity Rating Scale: initial validity and internal consistency findings from three multisite studies with adolescents and adults. Am J Psychiatry 2011;168(12):1266-1277.

20. Madan A, Frueh BC, Allen JG, et al. Psychometric Reevaluation of the Columbia-Suicide Severity Rating Scale: Findings From a Prospective, Inpatient Cohort of Severely Mentally Ill Adults. J Clin Psychiatry 2016;77(7):e867-873.

21. Stanley B, Brown GK. Safety planning intervention: a brief intervention to mitigate suicide risk. Cogn Behav Pract 2012;19(2):256-264.

22. Bryan CJ, May AM, Rozek DC, et al. Use of crisis management interventions among suicidal patients: Results of a randomized controlled trial. Depress Anxiety 2018;35(7):619-628.

23. Richards JE, Parrish R, Lee AK, Bradley KA, Caldeiro RM. An Integrated Care Approach to Identifying and Treating the Suicidal Person in Primary Care. 2019. https://www.psychiatrictimes.com/special-reports/integrated-care-approach-identifying-and-treating-suicidal-person-primary-care. Accessed 6 May 2019.

24. Patton MQ. Qualitative interviewing. Qualitative research and evaluation methods. Vol 3. Thousand Oaks: Sage; 2002:344-347.

25. Belli RF. The structure of autobiographical memory and the event history calendar: potential improvements in the quality of retrospective reports in surveys. Memory. 1998;6(4):383-406.

26. Feldman MD, Franks P, Duberstein PR, Vannoy S, Epstein R, Kravitz RL. Let's not talk about it: suicide inquiry in primary care. Ann Fam Med 2007;5(5):412-418.

27. Hudson DL. Quality Over Quantity: Integrating Mental Health Assessment Tools into Primary Care Practice. Perm J 2016;20(3):90-92.

28. Hom MA, Stanley IH, Joiner TE Jr. Evaluating factors and interventions that influence help-seeking and mental health service utilization among suicidal individuals: A review of the literature. Clin Psychol Rev 2015;40:28-39.

29. Malpass A, Dowrick C, Gilbody S, et al. Usefulness of PHQ-9 in primary care to determine meaningful symptoms of low mood: a qualitative study. Br J Gen Pract 2016;66(643):e78-84.

30. Muhr T. ATLAS. ti (Version 7)[Software]. 2004.

31. Hsieh HF, Shannon SE. Three approaches to qualitative content analysis. Qual Health Res 2005; 15(9):1277-1288.
32. Attride-Stirling $\mathbf{J}$. Thematic networks: an analytic tool for qualitative research. Qual Res 2001;1(3):385-405.

33. Henderson $\mathbf{C}$, Noblett $\mathbf{J}$, Parke $\mathbf{H}$, et al. Mental health-related stigma in health care and mental health-care settings. Lancet Psychiatry 2014; 1(6):467-482.

34. Van Tubergen F, Te Grotenhuis M, Ultee W. Denomination, religious context, and suicide: Neo-Durkheimian multilevel explanations tested with individual and contextual data. Am J Sociol 2005;111(3):797-823.

35. Van Orden KA, Witte TK, Cukrowicz KC, Braithwaite SR, Selby EA, Joiner TE Jr. The interpersonal theory of suicide. Psychol Rev 2010;117(2):575-600.

36. Youngstrom EA, Hameed A, Mitchell MA, et al. Direct comparison of the psychometric properties of multiple interview and patient-rated assessments of suicidal ideation and behavior in an adult psychiatric inpatient sample. J Clin Psychiatry 2015;76(12):1676-1682.

37. Frey LM, Fulginiti A, Lezine D, Cerel J. The Decision-Making Process for Disclosing Suicidal Ideation and Behavior to Family and Friends. Fam Relat 2018;67(3):414-427.

38. Lasalvia A, Zoppei S, Van Bortel T, et al. Global pattern of experienced and anticipated discrimination reported by people with major depressive disorder: a cross-sectional survey. Lancet. 2013;381(9860):55-62.

39. Ahmedani BK. Mental Health Stigma: Society, Individuals, and the Profession. J Soc Work Values Ethics 2011;8(2):41-416.

40. Pescosolido BA, Martin JK, Long JS, Medina TR, Phelan JC, Link BG. "A disease like any other"? A decade of change in public reactions to schizophrenia, depression, and alcohol dependence. Am J Psychiatry 2010; 167(11): 1321-1330.

41. Cohen LJ. Psychiatric hospitalization as an experience of trauma. Arch Psychiatr Nurs 1994;8(2):78-81.

42. Rochefort DA. Reimagining the Cuckoo's Nest. J Med Humanit 2017:112.

43. Grossman DC, Putsch RW, Inui TS. The meaning of death to adolescents in an American Indian community. Fam Med 1993;25(9):593-597.

Publisher's Note Springer Nature remains neutral with regard to jurisdictional claims in published maps and institutional affiliations. 